\title{
PENILAIAN SISTEM INFORMASI AKADEMIK MENGGUNAKAN MODEL COBIT 4.1
}

\author{
Muh. Aliyazid Mude \\ aliriset16@gmail.com \\ Universitas Muslim Indonesia
}

\begin{abstract}
Abstrak
Lembaga $\mathrm{XYZ}$ telah membuat sistem informasi akademik agar proses akademik berjalan lancar, namun selama ini belum ada penilaian pada sistem yang telah dibuat, apakah sistem itu sudah sesuai dengan standar pengelolaan IT atau belum. Karena itu penelitian ini menggunakan salah satu standar tata kelola TI yakni Cobit. Cobit Apabila tata kelola TI sesuai dengan standar yang diakui, maka pengelolaan dianggap layak dipercaya, Sehingga akan meningkatkan kepercayaan pengguna.. Adapun pendekatan yang digunakan adalah kualitatif dan kuantitatif. Pendekatan kualitatif dalam penelitian ini adalah data yang diperoleh melalui pengamatan (observasi) dan didasarkan pada penafsiran pemahaman peneliti secara subjektif. Hasil penilaian pada sistem yang diperoleh berada pada level 3 (defined). Artinya pemahaman pemakai (user) dalam menggunakan sistem belum merata dan terdapat masih ada kebijakan tata kelola IT yang belum lengkap.
\end{abstract}

Kata Kunci: Cobit 4.1; Penilaian; SIMAK; Tata Kelola TI

\section{Pendahuluan}

Sistem informasi akademik (SIMAK) yang diterapkan pada lembaga XYZ telah digunakan untuk membantu dan memudahkan sivitas akademik seperti dosen dan mahasiswa dalam menjalankan tugasnya. Dalam pengelolaan sistem tersebut belum ada penilaian yang terstandarisasi sebagai alat ukur atau panduan dalam mengelola sistem IT. Sehingga dengan penilaian ini pengelola IT dapat mengetahui sistem yang diterapkan sesuai standar atau tidak, bila sesuai maka akan dipertahankan atau ditingkatkan dan jika tidak, maka disarankan ada perubahan pengelolaan secara infrastruktur. Lembaga yang menggunakan pengelolaan IT secara standar yang diakui akan mendapatkan tingkat kepercayaan pada masyarakat atas kelayakan sistem tersebut. Yang pada akhirnya lembaga tersebut mengalami suatu kemajuan dalam layanan IT. Salah satu standar internasional yang diakui adalah Cobit. Cobit kepanjangan dari Control Objectives for Information and Related Technology. Dimana Cobit telah banyak digunakan oleh para peneliti tata kelola di seluruh dunia termasuk di Indonesia dalam Cobit terdapat 4 domain dan 34 proses TI. Adapun 4 domain yakni: (1) Plan and organize, proses ini memiliki fokus pada proses perencanaan dan penyelarasan strategi $\mathrm{TI}$ dengan strategi perusahaan; (2) Acquire and implement. Proses ini memiliki fokus pada proses pemilihan, pengadaan, dan penerapan teknologi informasi yang digunakan; (3) Deliver and support. Memiliki fokus pada proses pelayanan TI dan dukungan teknisnya; (4) Monitor and evaluate. Namun dalam hal ini hanya menggunakan domain deliver and support (DS). Untuk rumusan masalah bagaimana melakukan penilaian sistem informasi akademik menggunakan Cobit dan bagaimana memberi usulan perbaikan pada tata kelola TI. dari rumusan masalah ini kami membatasi masalah pada penggunaan DS1, DS2, DS4 dan DS8 domain DS, sehingga tujuan penelitian ini adalah memberikan penilaian pada sistem yang digunakan dan mengusulkan perbaikan tata kelola TI pada sistem (aplikasi) yang diterapkan di lembaga tersebut.

\section{Metode}

Dalam penelitian ini menggunakan model COBIT 4.1 domain DS. Gambar 2 memperlihatkan model Cobit 4.1. Model kematangan Cobit dimulai dari tingkat kematangan tidak 0 (tidak ada) sampai 5 (Optimised), tujuannya adalah untuk mengidentifikasi isu-isu organisasi dan bagaimana menetapkan prioritas untuk perbaikan. Sesuai Gambar 1 berikut: 


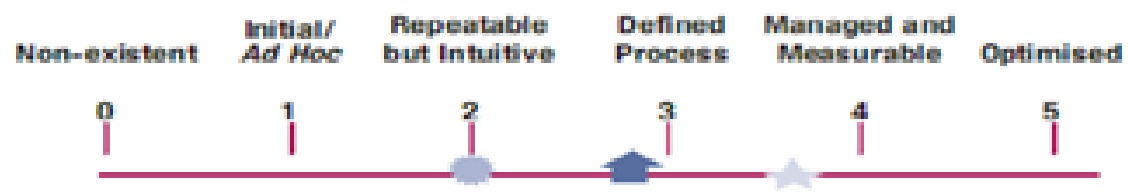

Gambar 1. Tingkat Kematangan

Tingkat kematangan pada Gambar 2 menunjukkan angka dari 0 sampai 5, yang mana tingkat paling bawah disebut sebagai non-existen artinya pengelolaan IT tidak diterapkan, kematangan tingkat 1 berarti pengelolaan belum terorganisasi dengan baik, tingkat 2 artinya pengelolaan IT biasa saja belum menggunakan otomatisasi, tingkat 3 artinya pengelolaan IT telah terdokumentasi dan telah dikomunikasikan, tngkat 4 ada pengontrolan dan pengelolaan IT sudah terukur dan tingkat 5 artinya pengelolaan IT lebih bagus dan terotomatisasi.

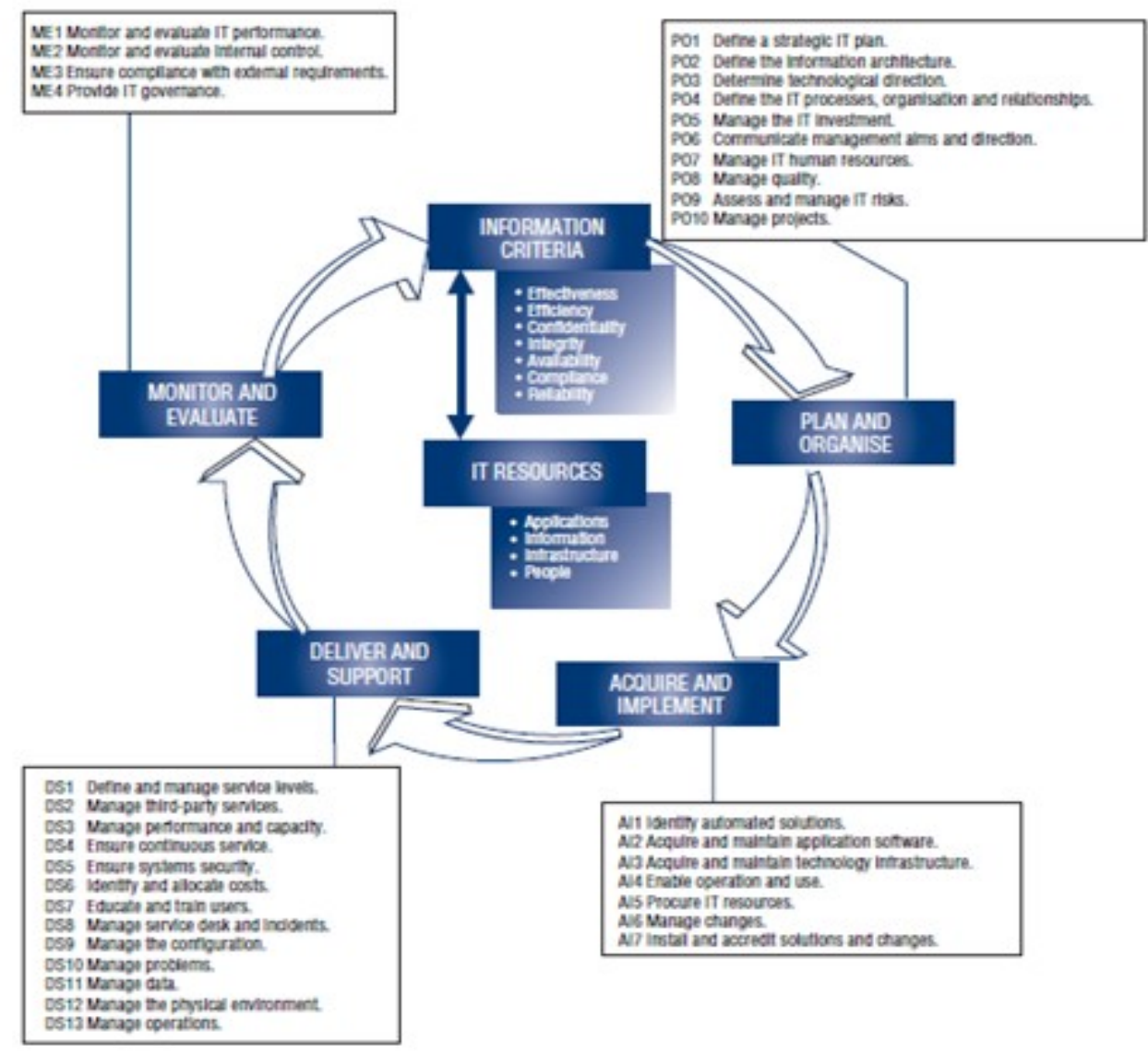

Gambar 2. Model Cobit 4.1

Pada Gambar 2 menunjukkan keterkaitan domain satu dengan domain lainnya. Ada 4 domain yang dimiliki dengan jumlah proses seluruh domain sebanyak 34 proses. Adapun domain yang digunakan pada penilitian ini adalah domain deliver and support (DS) yang terdiri dari 13 proses, namun hanya 4 proses DS yang dipilih sesuai dengan objek penelitian yakni: DS1 Define and manage service levels, DS2 Manage third-party services, DS4 Ensure continuous service dan DS8 Manage service desk and incidents. Adapun tahapan yang dilakukan terdiri dari 4 tahapan penelitian sesuai Gambar 3 sebagai berikut: 


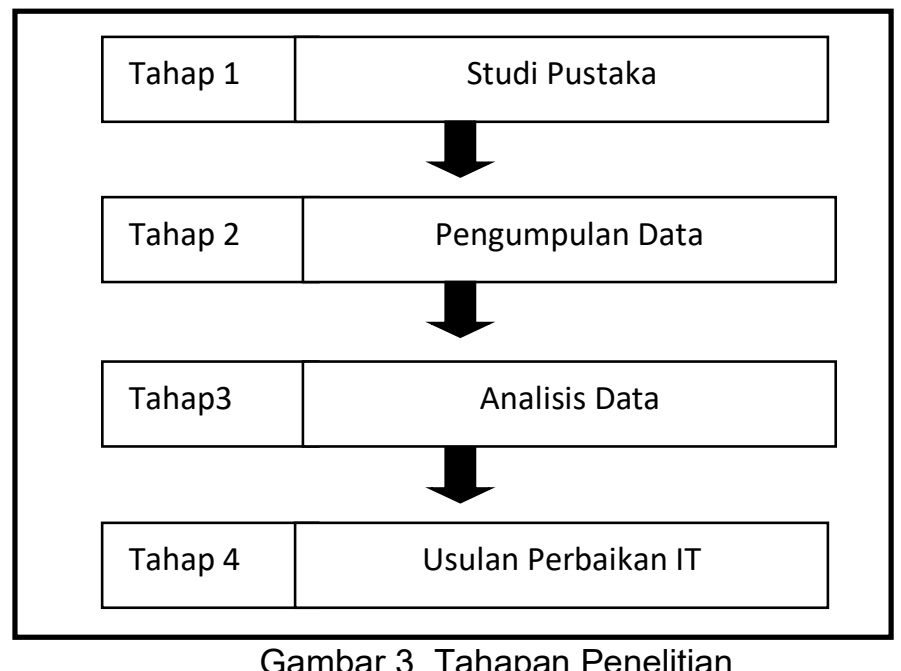

Gambar 3 Tahapan Penelitian

Gambar 2 menunjukkan beberapa tahapan penelitian yang dilakukan. Pada tahapan 1 studi pustaka didalamnya ada studi penelitian yang terdahulu kemudian mempelajari model cobit 4.1 khususnya pada domain DS1, kemudian memahami objek penelitian. hasil tahap ini diperoleh ilmu dasar dalam meneliti. Pada tahap 2 dilakukan pengumpulan data dimana dalam pengumpulan data ini beberapa hal yang dilakukan diantaranya: pembuatan kuesioner, menentukan dan mengambil data kuesioner. Setelah data dikumpulkan selanjutnya dilakukan tahapan 3 analisis data. Pada tahapan ini beberapa hal yang dilakukan diantaranya pengumpulan data, perhitungan data. Hasil perhitungan merupakan dasar menuju tahap 4 Usulan perbaikan pengelolaan IT. Adapun cara menilai menggunakan model Cobit dapat di ilustrasikan pada Gambar 4 berikut:

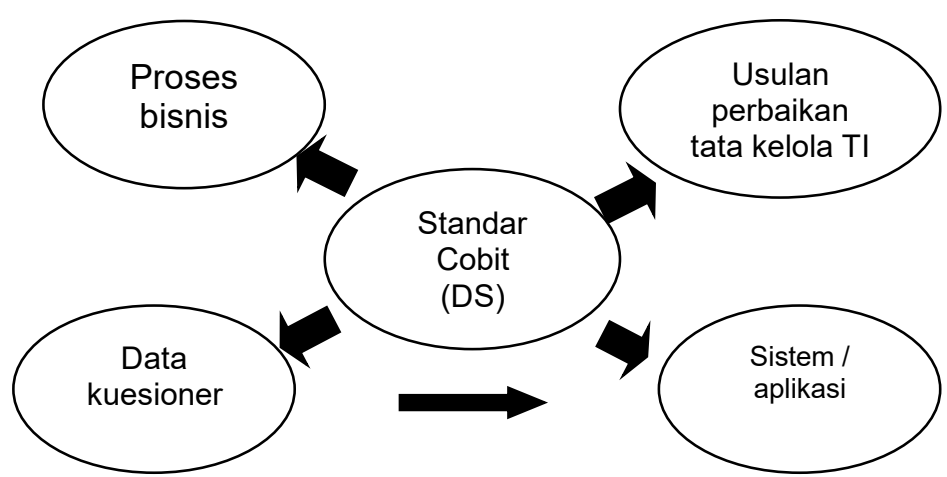

Gambar 4 Cara penilaian Sistem dengan Cobit

Model Cobit sebagai sentral untuk pemberian usulan perbaikan. Pengamatan pada proses bisnis yang sedang berjalan disesuaikan dengan DS pada standar Cobit, sehingga diperoleh data dari proses bisnis yang sedang berjalan. Pengamatan pada data kuesioner disesuaikan atau dicocokkan dengan sistem yang diterapkan untuk mendapatkan hasil yang sebenarnya. Pada pengamatan sistem (aplikasi) yang terkait dengan layanan kepada pemakai akhir disesuaikan dengan standar. Seluruh data dari hasil pengamatan yang dikaitkan dengan Cobit khususnya pada 4 proses DS, maka usulan perbaikan TI dapat diberikan sesuai model standar Cobit.

\section{Hasil dan Pembahasan}

Hasil yang diperoleh tiap level setelah dilakukan pengamatan yang sifatnya subjektif pada hasil kuesioner serta persepsi pengamatan pada sistem yang diterapkan, maka hasilnya sesuai Tabel 1. Pada Tabel 1 menunjukkan nilai maturity rata-rata diperoleh bukan nilai bulat, sementara tingkat kematangan sesuai model Cobit adalah nilai bulat Gambar 2, sehingga pembulatan tiap proses DS bernilai 3 atau defined. Hal ini berarti pemahaman pemakai sistem belum merata dan terdapat kebijakan tata kelola IT belum lengkap 
ILKOM Jurnal IImiah Volume 9 Nomor 3 Desember 2017

Tabel 1 Hasil tiap proses

\begin{tabular}{|l|c|c|}
\hline \multicolumn{1}{|c|}{ Proses DS } & $\begin{array}{c}\text { Nilai Maturity } \\
\text { yang diperoleh }\end{array}$ & $\begin{array}{c}\text { Pembulatan } \\
\text { Maturity yang } \\
\text { diperoleh }\end{array}$ \\
\hline (DS1) Define and Manage service & 2,93 & 3 \\
\hline (DS2) Define and Manage service & 2,88 & 3 \\
\hline (DS4) Ensure Continuous Service & 2,70 & 3 \\
\hline (DS8) Manage Service Desk and & 2,60 & 3 \\
\hline
\end{tabular}

Tabel 1 menunjukkan nilai yang diperoleh dari 4 proses DS yakni: (DS1) define and manage service 2,93, yang artinya prosedur pengelolaan TI yang dimiliki belum baik, namun standar penerapan pengelolaan diterapkan. (DS2) define and manage service memperoleh skor 2,88. Artinya pengelolaan TI telah memiliki prosedur dan dokumentasi dan kontrak sudah dibuat yang sesuai dengan form. (DS4) ensure continuous service memperoleh skor 2,70. Artinya Tanggung jawab pembagiannya pengelolaan sistem sudah jelas dan perencanaan tugas sudah jelas. Dan (DS8) manage service desk memperoleh skor 2,60. Ini bantuan layanan (help desk) sudah ada, fasilitas pertanyaan, tapi belum ada pedoman prosedur mengajukan pertanyaan. Pemakai berusaha sendiri menemukan fasilitas dan pencatatan belum terotomatisasi.

Usulan perbaikan pengelolaan TI diberi tiap proses mulai pada proses DS1, DS2, DS4 dan DS8. Adapun Usulan perbaikan sebagai berikut Mengelola tingkat layanan DS1 merupakan tanggung jawab (amanah) yang diberikan kepada petugas agar diatur sesuai dengan prosedur yang telah dibuat, menjaga dan memonitoring pelaksanaan tugas yang diberikan dan menghilangkan kewenangan secara pribadi untuk kepentingan bersama serta malakukan perbaikan sistem terus menerus. Membuat pos (help desk) dan prosedur layanan dibuat secara resmi (formal). Usulan perbaikan pada DS2 yakni prosedur yang terkait dengan layanan ke user agar di dokumentasikan dengan rapi, termasuk isi kontrak dan kesepakatan dengan pihak 3 , dokumennya dijaga dan disimpan dengan baik. Mengawasi dan menjaga hubungan dengan pihak 3 . Risiko dan masalah dibukukan (log book) dibukukan. Usulan perbaikan pada proses DS4, membuat laporan terkait layanan dilakukan secara prodik. Dan inventarisasi semua bentuk dokumen (komponen) terkait 22 layanan dengan rapi dan baik. Semua rencana terdokumentasi dan pelatihan atau workshop personil dalam hal layanan dilakukan secara priodik dan kontinyu. Menjaga dan memastikan pelayanan berkesinambungan. Dan untuk Usulan perbaikan pengelolaan TI DS8 yakni Melakukan evaluasi pada layanan yang diberikan dan mendokumentasikan dengan baik. dan melaksanakan pelatihan kepada personil agar pemahaman pada layanan dapat terukur. Memberi pedoman kepada user bagaimana prosedur penanganan insiden bila ada masalah terkait layanan.

\section{Kesimpulan dan Saran}

Usulan perbaikan pengelolaan TI didasarkan pada kematangan (maturity) di level 3 masingmasing DS. Agar pengelolaan TI berada pada level 3, pihak pengelola SIMAK memenuhi pengelolaan TI berikut: Semua prosedur telah dibuat dan distandarisasi serta didokumentasikan kemudian dikomunikasikan melalui pelatihan, namun pengelolaan TI masih berada pada level 3. Selanjutnya memenuhi kriteria maturity pengelolaan TI level 4 yakni: bahwasanya pengawasan dan pengukuran harus sesuai dengan prosedur. Proses layanan dilakukan perbaikan terus-menerus dan memberikan latihan kepada seluruh personil . Kegiatan yang terkait dengan sistem sudah terotomasi termasuk alat-alat pendukung misalnya sistem sudah terkait dengan sensor, CCTV dan lainnya. Adapun saran, untuk mendapatkan hasil yang maksimal, diharapkan menggunakan proses pada domain DS pada COBIT 4.1 yang belum digunakan yakni: DS3, DS5, DS6, DS7, DS9, DS10, DS11, DS12 dan DS13. Sehingga seluruh domain DS bisa diketahui penerapannya pada sistem IT yang diterapkan. 


\section{Daftar Pustaka}

[1] Haes, \& Grembergen. (2004). IT Governance and Its Mechanisms. Information System .

[2] ITGI. (2007). COBIT 4.1 framework control objetives management guidelines maturity models. USA: ISACA.

[3] Purwanto. (2010). Evaluasi Tata Kelola Teknologi Informasi Menggunakan Kerangka Kerja Cobit Dalam Mendukung Layanan Sistem Informasi Akademik Studi Kasus Universitas Budi Luhur . Telematika Mkom , 1-12.

[4] Rozas, I. S., \& Effendy, D. A. (2012). Mengukur Efektifitas Hasil Audit Teknologi Informasi cobit 4.1 berdasarkan perspektif end user. JURANAL LINK , 1-5.

[5] Sudarmawan. (2013). Evaluasi Pengendalian Sistem Informasi Akademik Menggunakan Framework Cobit 4.1. (Studi Kasus Stmik Amikom Yogyakarta). Yogyakarta: Stmik Amikom Yogyakarta.

[6] Surendro, K. (2009). Implemetasi Tatakelola Teknologi Informasi. Bandung, Jawa Barat, Indonesia: Informatika. 